\title{
PROCESSO E ESTRATÉGIA COMO PRÁTICA NA TOMADA DE DECISÃO: UM ESTUDO DE CASO
}

\author{
PROCESS AND STRATEGY AS PRACTICE IN DECI- \\ SION-MAKING: A CASE STUDY
}

\section{RESUMO}

Este estudo teve como objetivo compreender como ocorre o processo de tomada de decisão, a partir da análise das práticas estratégicas e da ação dos praticantes, em uma indústria de confecção. Para isso, foi realizada uma pesquisa qualitativa, por meio de um estudo de caso. Os dados coletados nas entrevistas semiestruturadas, observação direta e análise documental foram tratados com a técnica de análise da narrativa e pela triangulação de dados. Os resultados apontam que diferentes formas de análise do contexto organizacional têm gerado práticas importantes, como a adoção de ferramentas estratégicas, a exemplo da análise SWOT, planejamento estratégico e pesquisas de mercado. Essas práticas articuladas pelos praticantes da estratégia têm proporcionado à organização maior assertividade no processo de tomada de decisão.

Palavras-chave: Contexto Organizacional. Estratégia como Prática. Tomada de Decisão. Ação dos Praticantes.

Nathalia Berger Werlang nathaliabw@gmail.com Doutora em Administração. Centro Universitário FAI UCEFF. Itapiranga, Santa Catarina, Brasil.

Rosalia Aldraci Barbosa Lavarda rblavarda@gmail.com Universidade Federal de Santa Catarina, UFSC. Florianópolis, Santa Catarina, Brasil.

Liara Letícia Lorenzatto liara_lorenzatto@hotmail.com Bacharela em Administração. Centro Universitário FAI UCEFF. Itapiranga, Santa Catarina, Brasil.

\section{ABSTRACT}

This study aimed to understand how the decision-making process occurs through the analysis of strategic practices and practitioners' action in a confection industry. For this, a qualitative study was carried out, through a case study. The data collected in the semistructured interviews, direct observation and documental analysis were treated with the technique of narrative analysis and data triangulation. The results point out that different forms of analysis of the organizational context have generated important practices like the adoption of strategic tools such as the SWOT analysis, strategic planning and market research. These practices articulated by the practitioners of the organization have given greater responsiveness in the decision-making process.

Keywords: Organizational context. Strategy as practice. Decision making. Action of the practitioners. 


\section{INTRODUÇÃO}

A elaboração das estratégias empresariais é formada por meio de uma série de fatores internos e externos. Devido às contínuas transformações, que ocorrem na sociedade, os negócios sofrem pressões de todos os lados, para que consigam adaptar-se aos contínuos novos cenários que se apresentam, a fim de continuarem competitivos no mercado. Entretanto, não existe um modelo único de estratégia, que deve ser seguido por todas as empresas, há, sim, que se observarem as características internas e os fatores externos, que incidem sobre cada uma delas. Esses são elementos de preocupação central do campo da estratégia (CHAKRAVARTHY; DOZ, 1992), tanto nas pesquisas relacionadas ao conteúdo, quanto àquelas relacionadas ao processo estratégico.

A concepção de que não existe uma única forma de gestão de todas as empresas surge com a teoria contingencial, a partir dos anos de 1970 e 1980, ou seja, cada empresa precisa encontrar a melhor forma de se organizar a fim de alcançar seus objetivos (LAWRENCE; LORSCH, 1967).

Etzioni (1989) corrobora, ao afirmar que as organizações são unidades sociais, que compreendem diferentes objetivos organizacionais a partir de suas funções, que podem ser baseadas na busca pela legitimação a fim de justificar suas atividades, construção de padrões que possam avaliar sua eficiência, rendimento e análise de unidades de medida para justificar sua produtividade. Assim, a razão de ser da organização está baseada na resposta a esses objetivos, o que vai exigir a definição de diferentes estratégias.

Dessa forma, esse alinhamento e ajuste da estratégia organizacional com o ambiente podem ser compreendidos como um fenômeno social, um conjunto de práticas organizadas que estão sempre em (re)construção (CZARNIAWSKA, 2004, 2008, 2013; SCHATZKI, 2006), além do que a perspectiva de processo permite compreender em nível micro os aspectos relevantes de como as estratégias são moldadas e implementadas, na prática para dar resultado a essas demandas do ambiente (BURGELMAN et al., 2018).

A prática, como um movimento social, começou a ganhar força entre os anos de 1970 e 1980, uma vez que a relação entre teoria e prática ganhou destaque nas Ciências Sociais, especialmente no que se refere aos estudos organizacionais. Isso ocasionou uma "virada" para a ênfase à prática social (SCHATZKI, 2001), que se tornou uma alternativa em relação às teorias clássicas (RECKWITZ, 2002; FELDMAN; ORLIKOWSKI, 2011).

Diferente das abordagens reducionistas e individualistas, que buscam explicar os fenômenos sociais, a partir da ação individual ou na estrutura, a prática social considera que os indivíduos e as práticas são fenômenos que carregam um contexto histórico e social (RECKWITZ, 2002; FELDMAN; ORLIKOWSKI, 2011; SCHATZKI, 2005).

Assim, a virada da prática parte do pressuposto de que as organizações precisam ser analisadas como um processo contínuo, um acontecimento, bem como do resultado das diferentes interações sociais, que surgem a partir do processo de organizar (CZARNIAWSKA, 2004, 2008, 2013; SCHATZKI, 2006).

No contexto dos estudos acerca da estratégia, Jarzabkowski, Balogun e Seidl (2007) destacam que eles vêm sendo apresentados a partir da perspectiva da estratégia como prática, sendo esta a intersecção entre prática (atividade), praxis (ações pelas quais as atividades são desenvolvidas) e praticantes responsáveis pelo desenvolvimento da ação estratégica. Ademais, Jarzabkowski et al. (2015) destacam a influência do ambiente nas práticas estratégicas que, de acordo com o "como" serão desenvolvidas pelos praticantes, irão contribuir para o alcance dos resultados pretendidos.

Diante do exposto, este estudo teve como objetivo compreender como ocorre o processo de tomada de decisão, a partir da análise das práticas estratégicas e da ação dos praticantes em uma indústria de confecção. Para alcançar esse objetivo, realizou-se uma pesquisa qualitativa, por meio de um estudo de caso único 
(STAKE, 2003) em uma indústria do setor de confecções. O caso selecionado atende aos critérios de acessibilidade e intencionalidade (EISENHARDT, 1989), uma vez que a organização apresentou as características necessárias para a viabilização do estudo proposto.

As técnicas de coleta de dados foram entrevistas semiestruturadas, observação direta e análise de documentos disponibilizados pela organização. Para análise dos dados, foi adotada a técnica de análise da narrativa (LIEBLICH; TUVAL-MASHIACH; ZILBER, 1998) e comparação dos dados coletados.

O trabalho está estruturado da seguinte forma: após essa introdução, buscou-se aporte teórico para dar sustentação à coleta e à análise de dados, tratando-se da estratégia como processo (de tomada de decisão) e como prática. A seguir, apresentam-se os aspectos metodológicos da pesquisa. Posteriormente, são apresentados os resultados da pesquisa e, nas considerações finais, são abordadas as principais contribuições do estudo, limitações e sugestões de futuras pesquisas.

\section{TOMADA DE DECISÃO E ESTRA- TÉGIA COMO PRÁTICA}

As estratégias estão, cada vez mais, presentes nas organizações atuais, sendo observada sua importância nas ações das organizações, em curto, médio e longo prazo. Isso corrobora sua presença como um elemento fundamental para a sobrevivência e o desenvolvimento da empresa, conforme os objetivos que ela persegue.

O processo de tomada de decisão estratégica vem sendo discutido e pesquisado desde os primeiros estudos de estratégia, até as abordagens da renovação dos conceitos corporativos (CHAKRAVARTHY; DOZ, 1992; BULGACOV et al., 2007).

A tomada de decisão ocorre por meio de diferentes perspectivas, que podem ser consideradas como as decisões que são deliberadas, são tomadas de cima para baixo, como um processo centralizador; decisões do nível operacional, a partir de definições e demandas desde o chão de fábrica (emergentes) e decisões, que ocorrem no nível intermediário, porém, com a participação de todos os níveis hierárquicos (integradores) (ANDERSEN, 2004).

No modelo deliberado, somente o gestor da alta direção é capaz de ser habilitado a obter informações, que orientam a aplicação ou a execução (HAMBRICK, 1987). Aqui, uma pessoa sozinha não é responsável pelo sucesso na estratégia, mas, sim, o trabalho de uma equipe bem preparada e qualificada. Nesse modelo, o ambiente oferece oportunidades e ameaças para as organizações, que estabelecem os critérios de escolha.

Apesar de as pesquisas em estratégia aparecerem focadas em um modelo de tomada de decisão na alta direção (top-down), outras perspectivas começam a ter ênfase na literatura, as quais estão centradas na base da organização e são formadas pelo modelo bottom-up, por um lado e pelo modelo middle-up-down, por outro lado, possuindo uma visão mais empreendedora e democrática com uma estrutura hierárquica horizontal, ou seja, do meio e de baixo para cima e com ênfase nas pessoas. $\mathrm{O}$ processo na tomada de decisão é considerado descentralizado e possui um ambiente orgânico, ou seja, com uma visão mais participativa (ANDERSEN, 2004; LAVARDA; GINER; BONET, 2011; MIRABEU; MAGUIRE; HARDY, 2018).

Assim, o campo de estudos em estratégia vem sendo (re)demarcado por múltiplas abordagens teóricas, entre as quais se tem destacado o dualismo entre processo e conteúdo (BULGACOV et al., 2007), a depender do modo como se entende o praticante, pois é ele quem irá dizer o sentido que a estratégia possui. Dessa forma, olhar a estratégia como uma prática social é olhar como ela é; como as pessoas fazem e como ela está situada. A estratégia passa a ser compartilhada, reproduzida ao longo do tempo, e as pessoas pressupõem que, para fazer negócios, é preciso estratégia; isso significa uma prática social. Assim, a perspectiva que se passa a analisar para entender a estratégia é a da prática social, ou seja, considera-se a virada da prática para analisar a estratégia a par- 
tir da perspectiva micro, do dia a dia, da ação (SCHATZKI, 2001; RECKWITZ, 2002; ORLIKOWSKI, 2007; NICOLINI, 2012; CZARNIAWSKA, 2013).

O tema estratégia como prática ou strategizing surgiu nos estudos de estratégia, nos anos de 1990, com Whittington (1996) e vem sendo discutido e expandido em diversos estudos contemporâneos, como Balogun, Huff e Johnson (2003), Jarzabkowski, Balogun e Seidl (2007), Chia e Mackay (2007), Rasche e Chia (2009), Jarzabkowski (2010), Lavarda, Canet-Giner e Peris-Bonet (2010), Cardoso e Lavarda (2015), Jarzabkowski, Burke e Spee (2015), Iasbech e Lavarda (2018).

O estudo de Whittington (1996) foi responsável por disseminar o conceito de "strategy as practice", por meio da definição do conceito como prática social, voltando os olhares para os praticantes das estratégias e suas interações.

Jarzabkowski (2003) ampliou o conceito de estratégia como prática, ao afirmar que ela é composta por um agrupamento de interações e interpretações dos colaboradores, que estão à frente de atividades estratégicas de uma empresa. Assim, as ações do dia a dia passam a ser valorizadas e investigadas, a partir da estratégia como prática, que são resultantes das atividades habituais de uma empresa (JOHNSON; MELIN; WHITTINGTON, 2003).

A partir desses estudos, a estratégia vem sendo vista como atividade micro-organizacional, ou seja, como atividades diárias dos membros da organização que podem ser consideradas estratégicas para qualquer empresa (JOHNSON; MELIN; WHITTINGTON, 2003; JARZABKOWSKI, 2003; VAN DE VEN; JOHNSON, 2006).

Jarzabkowski (2004) define a estratégia como prática por um conjunto de atividades que envolvem normas, regras, rotinas, hábitos e processos que os atores desenvolvem a partir de demandas. Além disso, a autora sugere que as práticas podem ser classificadas como racionais e administrativas, relativas a atividades organizacionais e direção; discursivas, relativas aos símbolos e aos resultados gerados na interação entre os atores envolvidos nas ações episódicas, que geram interação entre os praticantes no decorrer da execução da estratégia.

Justamente por isso, essa vertente de investigação de estratégias recebeu o nome de estratégia como prática, uma vez que compreende que a estratégia é construída, diariamente, pelos atores envolvidos no processo durante suas atividades e rotinas de trabalho (WHITTINGTON, 2006). Assim, a estratégia pode ser definida pelas atividades que os membros executam e não apenas como uma atividade definida pela alta direção (VAN DE VEN; JOHNSON, 2006).

Bulgacov et al. (2007) corroboram a visão micro-organizacional da estratégia como prática, uma vez que o foco de investigação se concentra tanto no processo de formulação e implementação da estratégia, quanto nas atividades diárias dos funcionários, à medida que se relacionam as atividades habituais aos resultados organizacionais.

De acordo com Jarzabkowski, Balogun e Seidl (2007), o strategizing ocorre por meio da interação de três elementos, que são as práticas, a práxis e os praticantes, figura 1. As práticas são caracterizadas pelas rotinas, pelos procedimentos e pelas normas que surgem da estratégia; entretanto, acontecem de uma forma relacionada à cultura organizacional, ou seja, surgem da cultura já enraizada na organização (JARZABKOWSKI; BALOGUN; SEIDL 2007).

Ainda, para Whittington (2006), as práticas são compreendidas como rotinas e procedimentos comportamentais que envolvem questões da cultura organizacional, como tradições e normas das organizações. 
Figura 1 - Strategizing: um modelo conceitual para analisar a Estratégia como Prática

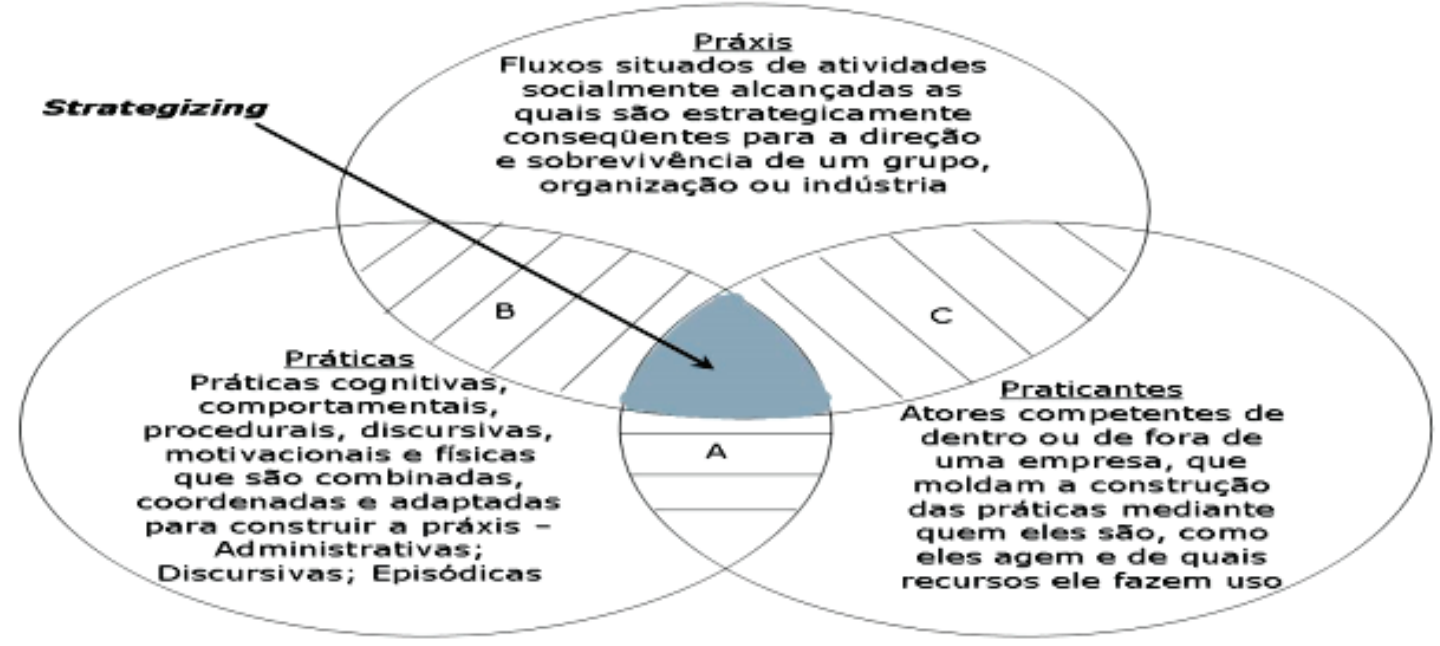

Fonte: (JARZABKOWSKI; BALOGUN; SEIDL, 2007, p. 11).

A práxis é definida por Jarzabkowski, Balogun e Seidl (2007) como as interligações que existem entre as ações dos atores envolvidos na instituição, assim como as ações desempenhadas por eles, a fim de alcançar as metas previamente definidas.

Já os praticantes são representados pelos atores, que desenvolvem essas ações. São indivíduos que fazem parte da organização, em que, diariamente, são realizadas as práticas estratégicas. São considerados praticantes todos os atores organizacionais, sejam eles da base, intermediários, sejam do topo da pirâmide organizacional (JARZABKOWSKI; BALOGUN; SEIDL, 2007).

Dessa forma, Whittington (2006) destaca que os atores podem ser considerados os elementos-chave na abordagem da estratégia como prática, uma vez que são eles quem estão inseridos nas organizações e realizam as práticas. Sendo assim, são eles que auxiliam na formação e na implementação das estratégias. Além deles, os consultores e outros atores externos que possam contribuir com a organização também podem ser considerados praticantes, uma vez que contribuem para a estratégia organizacional.

Por isso, Whittington (2006) destaca que o ambiente interno e externo da organização se une, a partir do momento em que as experiên- cias, vividas pelos praticantes no ambiente externo, passam a integrar o ambiente interno da empresa, a partir das práticas.

Sendo assim, a partir da visão da estratégia como prática, acredita-se que a identidade das pessoas da organização afeta a forma de como as estratégias são definidas. Nesse contexto, os estrategistas (praticantes), a partir de seu conhecimento e experiências, auxiliam no desenvolvimento e no molde das estratégias, fugindo do processo deliberado e de atribuição de responsabilidades (JARZABKOWSKI; BALOGUN; SEIDL, 2007).

Adicionalmente, Canhada e Bulgacov (2011) reafirmam que a estratégia, como prática social, tem como foco as atividades realizadas pelos indivíduos em nível micro-organizacional, que, ao interagirem e estarem envolvidos com relações de poder complexas, podem trazer os resultados esperados ou não pela organização.

Whittington, Cailluet e Yakis-Douglas (2011) adotam uma abordagem diferente para a estratégia, como prática, na qual ela não é considerada deliberada e, sim, emergente, ou ainda, aberta, uma vez que aumenta a flexibilidade e a inclusão de atores e processos, à medida que se desenvolve na prática. Assim, ela envolve a participação de todos os atores na troca de informações e na aceitação de diferentes pontos 
de vista, a fim de tornar a estratégia mais alinhada com todos os níveis organizacionais.

O estudo realizado por Teixeira e Costa (2012) buscou compreender a realidade de uma empresa multinacional catarinense do setor moveleiro a fim de identificar como a estratégia, como a prática é relevante nesse contexto. Sendo assim, a empresa que evoluiu de uma organização de fundo de quintal para uma multinacional, parceira com uma empresa italiana, utilizou-se da estratégia como prática uma vez que o modelo de produção, a incorporação da tecnologia italiana e os atores organizacionais, que foram treinados na Itália, contribuíram, fortemente, para a transformação da empresa.

Este estudo corrobora os achados de Jarzabkowski et al. (2015), os quais enfatizam a importância de estudar a prática no momento em que ela acontece e, da mesma forma, acompanha as atividades, à medida que elas ocorrem, a fim de evidenciar se existem lacunas entre a prática que foi formalizada e o que realmente acontece no dia a dia e, assim, evidenciar o que se chama de improvisações, ou ainda, escolhas alternativas.

Ao analisar o sucesso de fenômenos, que ocorrem ao longo do processo, Tureta e Júlio (2015) afirmam que todos os desafios enfrentados antes e durante o desfile de uma escola de samba foram superados a partir do momento em que os praticantes foram superando os desafios ao longo do percurso e conseguiram atingir o resultado esperado no fim do desfile.

Ainda, quando se analisa a importância dos atores externos para o sucesso das estratégias organizacionais, D`avila et al. (2016) analisaram quais membros externos seriam relevantes a partir da visão dos empresários e o trabalho realizado por eles para as estratégias organizacionais.

Dias, Rossetto e Marinho (2017) realizaram um estudo a fim de compreender como as práticas discursivas contribuíram no fazer estratégia de uma instituição de ensino superior comunitária. Partindo de um estudo de caso único, os dados foram coletados por observações em reuniões de planejamento estratégico, análise documental e entrevista com responsá- veis de cinco níveis hierárquicos da IES. Assim, os resultados apontam que a prática estratégica na instituição ocorre a partir de seu contexto histórico-social, da relação de poder dos diferentes estrategistas, das vozes dos praticantes e de seu processo de decisão.

Diante do exposto, percebe-se que inúmeros estudos vêm apresentando resultados decorrentes da interação da estratégia, como processo e prática, podendo ilustrar como é possível que decisões estratégicas possam ser tomadas, considerando o dia a dia da organização. Dessa forma, buscando responder à questão de pesquisa inicialmente proposta, elaborou-se a proposição decorrente da revisão teórica realizada, para guiar a pesquisa de campo e ser comparada com os dados coletados empiricamente. A tomada de decisão estratégica é definida a partir da análise do contexto organizacional (ambiente) e da ação dos praticantes (práticas estratégicas).

\section{PROCEDIMENTOS METODOLÓGICOS}

Para justificar as diferentes abordagens epistemológicas, quando estamos tratando de estratégia como processo e estratégia como prática (BURGELMAN, 2017; BURGELMAN et al., 2018), a metodologia adotada se apoia na fronteira de paradigmas, apresentada por Silva e Roman Neto (2006), considerada perspectiva multiparadigmática, defendendo que existe uma zona de transição entre os paradigmas funcionalista e interpretativo, os quais apresentam similaridades mais que diferenças em seu cruzamento.

Para atender ao objetivo do presente estudo, realizou-se uma pesquisa qualitativa, descritiva, sendo orientada pelo método de estudo de caso. De acordo com Stake (2003), o estudo de caso favorece a pesquisa empírica em que se estuda um fenômeno contemporâneo em profundidade e em seu contexto de vida real. Com esse método, buscou-se obter experiências de empresários gestores de uma empresa de confecção situada em um polo têxtil no sul do Brasil, a partir da narrativa de tomada de decisão 
em diferentes episódios estratégicos relevantes, considerando a busca em compreender, de forma aprofundada, o fenômeno no contexto em que ele ocorre, por meio do ponto de vista e do entendimento dos atores envolvidos (praticantes). O estudo de caso foi desenvolvido a fim de aprofundar a questão de pesquisa; para isso, buscou-se verificar diferentes fontes de evidências. O caso foi selecionado, seguindo os critérios de acessibilidade e intencionalidade (EISENHARDT, 1989), uma vez que a organização apresenta as características necessárias para viabilizar o estudo proposto.

A empresa do setor têxtil, já está, há mais de 25 anos, no mercado, possui quatro unidades produtivas no estado catarinense, além de escritórios corporativos em São Paulo. A seleção do caso em estudo no setor têxtil justifica-se pelo fato de o Brasil ser, atualmente, o $2^{\circ}$ maior empregador da indústria de transformação e $2^{\circ}$ maior gerador do primeiro emprego; é o $4^{\circ}$ maior parque produtivo de confecção do mundo; $5^{\circ}$ maior produtor têxtil do mundo; $4^{\circ}$ maior produtor de malhas do mundo e faturou, em 2015, US\$ 39,3 bilhões (ABIT, 2016).

Sendo assim, buscou-se compreender o processo de tomada de decisão, a partir da análise das práticas estratégicas e da ação dos praticantes em uma indústria de confecção.

Em relação à técnica de coleta de dados utilizada, foram empregadas três diferentes fontes de investigação, proporcionando, assim, a triangulação dos dados, por meio da realização de entrevistas, observação direta e análise documental. As entrevistas semiestruturadas foram realizadas com quatro gestores de nível médio da empresa, uma vez que eles possuem relação direta com os gestores do topo da pirâmide, assim como com os praticantes da base. O instrumento de coleta de dados, que foi utilizado nesta pesquisa, foi adaptado do instrumento de Krakauer (2011).

Por questões éticas, os participantes foram convidados, previamente, a participar da pesquisa, assinando um termo de aceite. Além disso, as entrevistas foram gravadas e, posteriormente, transcritas para facilitar a análise.
Assim, a coleta de dados priorizou o processo de tomadas de decisões estratégicas e como as vozes dos praticantes são utilizadas para a formação das estratégias. Além das entrevistas, foram realizadas observações diretas em três reuniões de planejamento estratégico da empresa, nas quais se procurou observar o padrão de comportamento, a formação das decisões e a forma de atuação in loco. As observações buscaram responder à questão de pesquisa que orientou o estudo (Como ocorre o processo de tomada de decisão a partir da análise das práticas estratégicas e da ação dos praticantes?).

Foi também realizada a análise documental a partir de relatórios de crescimento da empresa e das atas de reuniões de decisões estratégicas fornecidas para o estudo.

Com base nas diferentes fontes de coleta de dados, foi possível realizar a triangulação dos dados (MINAYO; ASSIS; SOUZA, 2005). Esse procedimento permite a integração de diferentes fontes de evidência, proporcionando a minimização dos vieses e ampliando a confiabilidade dos dados.

Para a tabulação dos dados, foi utilizada a técnica de análise da narrativa, que procura entender a totalidade do fenômeno, a partir de suas peculiaridades (GODOI; BANDEIRA-DE-MELLO; SILVA, 2006). As narrativas são transcritas com intuito de representar as evidências encontradas no campo.

Assim, passa-se para a apresentação e a análise dos resultados, desenvolvidas de forma conjunta (resultados das entrevistas, observação e documentos), considerando-se a abordagem indutiva proposta por Trochim (1989) em que se apresentam os dados empíricos e volta-se à teoria, contemplando e corroborando (ou não) os achados da pesquisa.

\section{APRESENTAÇÃO E ANÁLISE DOS RESULTADOS}

A empresa, em estudo, está localizada no Município de São Carlos - SC (matriz) e possui mais cinco unidades no Brasil. Sua conjuntura societária é formada por dois sócios e está atu- 
ando no mercado há 25 anos. São 536 funcionários diretos, mais 68 representantes comerciais; apresentou, em 2014, um faturamento acima de R\$3.600.000,00. O setor de atuação é o do ramo de confecção.

Os gestores foram identificados como Entrevistado A, Entrevistado B, Entrevistado $\mathrm{C}$ e Entrevistado D. Inicialmente, os gestores foram questionados acerca das decisões estratégicas mais relevantes, que tiveram que ser tomadas nos últimos seis meses. $\mathrm{O}$ quadro 01 apresenta estes resultados.

Quadro 1 - tomada de decisão estratégica

\begin{tabular}{|c|c|c|}
\hline Gestores & Cargo & Tomada de decisão estratégica \\
\hline Entrevistado A & Gerente de recursos humanos & $\begin{array}{l}\text { Planejamento, implementação e gestão do } \\
\text { programa de cargos e salários }\end{array}$ \\
\hline Entrevistado B & Gerente comercial & Reestruturação da área de mercado \\
\hline Entrevistado C & Sócia-proprietária e gerente administrativa & Investimentos na infraestrutura \\
\hline Entrevistado D & Gerente de infraestrutura & Ampliação do parque fabril \\
\hline
\end{tabular}

Fonte: elaboração própria

Ao analisar o ambiente externo, que é levado em consideração para a tomada de decisão, os gestores destacam alguns fatores principais, como análise de variáveis do governo, variáveis da população e características demográficas, realização de pesquisa de concorrentes, fornecedores, clientes e tecnologia, que influenciam na tomada de decisão, para o que ressaltaram:

Verificamos o conjunto de todos, porque a gente olha cenário político, cenário econômico, cenário de consumo, como é que está o varejo que é a nossa área de atuação, que pacote de valor vamos levar para o mercado, que pacote de valor vamos levar para o colaborador, porque ele também precisa desejar trabalhar em nossa empresa, olhamos concorrência, olhamos comportamento de consumo, porque a gente trabalha com a renda discricionária do consumidor (Entrevistado C);

Basicamente variáveis relacionadas a concorrentes, fornecedores, clientes e tecnologia em primeira instância e também referente à população e suas características, onde nós estamos produzindo, então, qual é a disponibilidade de mão de obra, qual é o tipo de mão de obra, vou ter que ter treinamento, automação ela me ajuda a reduzir essa dependência (Entrevistado D);

Levamos todas as variáveis em consideração, não tem como trabalhar essas variáveis separadamente, a gente sempre tem que estar com a visão da floresta, a gente usa muito isso, olhar e enxergar uma floresta não somente uma

árvore e uma floresta têm esses quatro itens, todas essas variáveis, são importantes de serem analisadas, aí claro, na tomada de decisão a gente compunha, liquidifica isso e toma a decisão que a gente certamente fazendo uma escolha a gente vai priorizar uma variável e vai, talvez, deixar as outras um pouco mais de lado (Entrevistado A).

A partir da narrativa dos entrevistados, pode ser examinado que todos os gestores levam em consideração um conjunto de variáveis externas para a tomada de decisão, evidenciando a influência do ambiente (contexto) no processo interno, que vai ser moldado pelas ações dos gestores (praticantes), podendo resultar em diferentes escolhas estratégicas ou em melhores práticas, conforme proposto por Jarzabkowski et al. (2015, p.15) traduzido na figura 2.

Acerca dos fatores relevantes, para a formação das estratégias, os respondentes ainda afirmam que: "os fatores considerados para a formação das estratégias são aumento da produtividade, redução de custos e melhoria da 
qualidade do produto final." O entrevistado (A) alegou que "números, resultados, fatos e dados, feeling não adianta, é muito indicador, se lá apresenta que deve ser, assim será", confirmando o que pode ser encontrado em Mirabeau e Maguyrre (2014) quando apresentam a relação entre estratégia como processo e como prática com as diferentes manifestaões da estratégia (desde deliberada, passando por emergente até ser realizada). tecnológicos e discussões com a equipe. Os demais entrevistados destacaram que

Para a tomada de decisão se considera tudo, é a visão da equipe, pois são eles que acompanham os indicadores e esses indicadores obviamente só alguns são tratados em nível de diretoria; não se vem aqui tratar diretamente sobre absenteísmo, pois isso eu trato na mi-

Figura 2 - Modelo integrativo de estratégia como prática

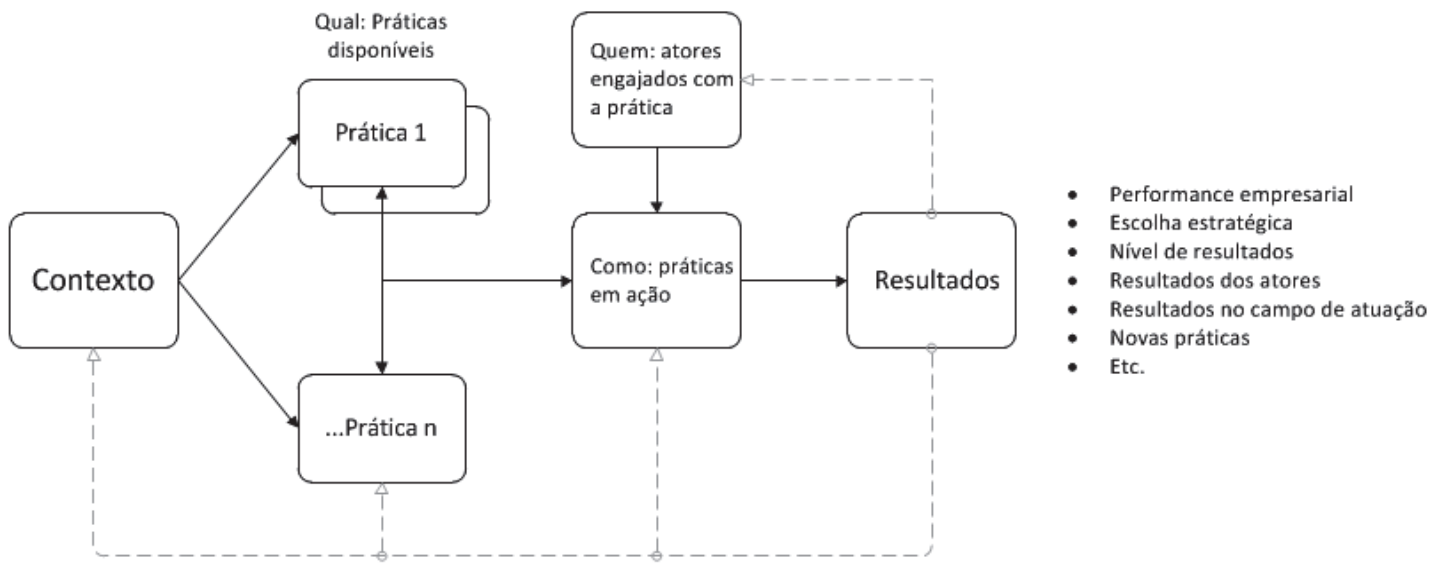

Fonte: (JARZABKOWSKI et al., 2015, p. 15).

O entrevistado B enfatizou que "foi a questão da posição que a empresa quer seguir, que é ter a cabeça de mercado, a necessidade de crescimento, porque a gente tinha um estudo de mercado que dizia que a marca poderia crescer, mas que precisava realmente buscar essas adequações".

De maneira complementar, o entrevistado $\mathrm{C}$ afirma que o principal fator para a formação da estratégia organizacional é o mercado consumidor, "existe potencial de mercado a ser coberto, nós fizemos um mapeamento de mercado no Brasil todo, com alguns indicadores externos, em nível de IBGE, índice de potencial de consumo das regiões e das cidades e mapeamos o perfil das cidades, onde a empresa poderia estar presente".

Quando questionados sobre a importância da tecnologia para a tomada de decisão, o entrevistado D alegou que sempre usa recursos nha equipe, crio o plano de ação lá junto com os ambientes onde estão com maior defasagem, a gente trata, por exemplo, o indicador de rotatividade, esse é tratado em diretoria, então, a gente alinha tudo, precisa do recurso tecnológico, com base em BI, RP, planilha também, excel, percepção da equipe (Entrevistado A); A gente discute muito com a equipe, nós temos banco de dados, BI, planilhas de Excel, gráficos, pesquisas. É discutido com a equipe e as decisões são compartilhadas, a gente discute tudo que tem que discutir antes de escolher, depois que escolheu, parte para a cobrança, cada um assume um pedaço da tarefa. Há uma discussão muito intensa para a tomada de decisão, quando o grupo escolheu um caminho, todo mundo dá as mãos e segue para o mesmo foco (Entrevistado C). 
"Sim, muitas planilhas, muitas discussões com a equipe, pesquisas também, a gente tem também sistemas próprios, como BI interno, onde a gente consegue montar alguns cenários específicos para análise e cruzamento de dados específicos." (Entrevistado B).

Diante do exposto, entende-se que todos os gestores analisam as informações do ambiente considerando os recursos tecnológicos e ferramentas (estratégicas em uso), segundo Jarzabowski e Kaplan (2015), como planilhas, cenários, sistemas integrados, BI, discussões com a equipe, as quais favorecem, contribuem para o processo de tomada de decisão.

A partir das ferramentas utilizadas para análise e discussão das ideias, o entrevistado C evidencia que a equipe consegue, por exemplo, mapear as novas estratégias a serem seguidas pela empresa, por meio do desdobramento de uma diretriz. Nesses momentos, a empresa consegue traçar estratégias para o lançamento da nova coleção, preço, custo, em que o produto será fabricado, quem vai produzir, a qual preço e como será feita a comunicação no mercado.

Quanto à forma de gestão praticada pela empresa, perante seus empregados, para melhor tomada de decisão, o entrevistado A afirmou que

Todas as decisões são tomadas de forma colegiada, o RH participa efetivamente no planejamento estratégico, porque quem conduz todas as estratégias são as pessoas. [...] às vezes o dono tem uma intenção, mas os dirigentes (nós) definem por outro direcionamento, obviamente apresentando fatos e dados.

De maneira complementar, o entrevistado D afirma que é preciso ouvir o operador do chão de fábrica, que conhece, de fato, o processo, já que a teoria nasce da prática. Entretanto, o mesmo entrevistado ainda afirma que "não por isso se deve abrir mão de ferramentas de análises, como investimentos, retornos, etc".

Percebe-se, aqui, que a empresa possui uma forma de gestão bastante participativa, visto que são levadas em consideração as opiniões de todos os níveis hierárquicos no momento de tomada de decisões, aproximando, na realidade estudada, o processo de tomada de decisão da prática diária, da ação, conforme previsto em Burgelman et al. (2018).

Quando indagados sobre os fatores que influenciam na formação da estrutura da empresa para tomada de decisões, o entrevistado A apontou que a tomada de decisão é toda realizada por meio de processos mais formais que informais. Os demais entrevistados citaram que

Nós sempre trabalhamos muito com consultoria na empresa, então, a gente segue métodos academicamente comprovados, a exemplo do BSC, dos indicadores econômicos financeiros, benchmarking, etc. A gente contrata programas de fora, contratamos consultores, professores, ficamos de olho por onde vai a política, por onde vai a economia, como está o câmbio. Então, não dá para seguir somente pesquisas e orientação acadêmica, tem que ter um pouco de percepção de mercado, para poder acertar mais. Se você não se cercar de alguns indicadores o erro é maior, e por isso que a empresa precisa muito do planejamento estratégico e orçamentário, tem muita técnica no nosso trabalho sim, não é amador (Entrevistado C).

De acordo com as narrativas, verifica-se que o processo de identificação da necessidade da informação pareceu ser formal e pouco intuitivo em todas as decisões descritas. Entretanto, os autores Eisenhardt e Zbaracki (1992) acreditam que a intuição está presente no processo de decisão e age como complementar a racionalidade.

Corroborando essas afirmações, Keeney (2004) destaca que um bom tomador de decisão sempre avalia, em qualquer nível de decisão, todas as informações de que dispõe sobre o assunto. É muito difícil utilizar a intuição para todas as decisões complexas, como é o caso das estratégias, apesar de ser necessário empregar certo grau de subjetividade. Faraco, Lavarda e 
Gelbcke (2019) destacam as dimensões objetivas e (inter)subjetivas no processo de tomada de decisão estratégica, assim como a complexidade dos papéis estratégicos dos gestores intermediários diante de situações deliberadas e emergentes, apontando a necessidade, em especial, de aprimoramento cotidiano das concepções incrementais (conhecimento, experiência, sensibilidade, julgamento, entre outras).

Ao analisar a tomada de decisão estratégica na empresa, a partir das ferramentas estratégicas: BSC, Planejamento estratégico, Planejamento orçamentário e Medidas mensais sistemáticas de todos os resultados, o entrevistado $\mathrm{C}$ afirmou que

Nós fazemos uma reunião mensal, chamada AGIR (Avaliação Gerencial de Indicadores de Resultados) com os gerentes e cada gerente faz com suas equipes, mensalmente, há uma disseminação de resultados, para que ele permeie todos os níveis da organização, então, acho que isso foi uma habilidade que a empresa construiu e que tem nos trazido esses resultados positivos [...] e é isso que vai levar a empresa em um posicionamento de destaque ao longo dos anos, a construção dessa cultura, dessa disciplina, desse compartilhar da gestão. Trabalhamos com balanço, com todas as ferramentas acadêmicas, aquilo que a gente aprende na faculdade a empresa aplica, mas algumas coisas tem que respeitar a intuição, tem que sentir a hora de dar o salto e a hora de puxar o freio de mão [...]. Se você não se cercar de alguns indicadores o erro é maior, por isso que a empresa precisa muito do planejamento estratégico e orçamentário.

Ao refletir sobre a narrativa dos entrevistados, verificou-se que a empresa utiliza o método BSC (Balanced Scorecard), que, de acordo com Kaplan e Norton (1997), oferece aos executivos os instrumentos necessários para alcançar o sucesso futuro. Hoje, as empresas, competem em ambientes bastante complexos.
É fundamental que exista uma perfeita compreensão de metas e métodos para alcançá-los. O BSC traduz a missão e a estratégia das empresas, em um conjunto abrangente de medidas de desempenho que serve de base para um sistema de medição e gestão estratégica.

Além disso, o planejamento estratégico definido, as avaliações mensais e as medidas sistemáticas dos resultados são outros fatores utilizados pela empresa para auxiliar nas tomadas de decisões. A utilização dessas ferramentas também ficou evidente no momento em que foi realizada a observação direta na empresa, quando se pode acompanhar uma das reuniões mensais realizadas pela equipe de gestores, na qual são tomadas decisões futuras para a empresa, com base nos indicadores de resultados mensais.

Nessa oportunidade, também foi evidenciada a existência de um Planejamento Estratégico definido e estruturado, assim como o BSC e o Mapa estratégico da empresa. Essas ferramentas evidenciam dois pontos: a formação da estratégia, que é deliberada (formalmente nos planos expostos) e emergente quando são discutidos para ser revisados em função de mudanças do ambiente interno ou externo, como mostra a teoria (MIRABEAU; MAGUYRRE; HARDY, 2018) e, simultaneamente, a estratégia como prática evidenciada nas ações e na participação dos praticantes nos episódios estratégicos, como a reunião em si ou a participação traduzida nas ações diárias para consecução dos planos (BURGELMAN et al., 2018).

Ao buscar compreender quem são os praticantes nessa organização, identificou-se quem são os atores responsáveis pelas tomadas de decisões, quadro 02. 
Quadro 2 - Praticantes (desenvolvem a prática estratégica)

- Colegiada (acionistas, direção, presidência, diretoria e juntos tinham alguns gestores, da

Atores área de mercado, da área de operações, RH);

- Próprios gestores;

- Gestores e operacional.

Fonte: elaboração própria

Nos relatos dos gestores, identificou-se que: "Foram em reuniões que começamos a fazer junto com a fundação Dom Cabral e aí as coisas começaram se construir, foi junto obviamente com os acionistas, direção, presidência, diretoria e juntos tinham alguns gestores, da área de mercado, da área de operações" (Entrevistado B); ademais

$\mathrm{Na}$ verdade todas as decisões são feitas de forma colegiada, o RH participa efetivamente no planejamento estratégico, porque quem conduz toda as estratégias são as pessoas, isso é recente, a empresa já trabalha o planejamento estratégico há mais tempo, mas há dois anos que eu estou na empresa, logo em seguida, uns quatro meses depois a gente conversou sobre isso para inserir efetivamente a área de recursos humanos no planejamento não somente na execução, então, o RH participa efetivamente. Todas as decisões na verdade não vem do dono, às vezes é até o contrário, o dono tem uma vontade uma intenção, mas os dirigentes, os colegiados como a gente chama definem por outro direcionamento, obviamente apresentando fatos e dados (Entrevistado A);

Você tem que ouvir a intuição do operacional, porque na realidade a teoria nasce da prática, quando você pratica, observa os fenômenos e extrai algum conhecimento que pode ser replicado; [...] o pessoal da manutenção, os operadores foram consultados a respeito de qual o melhor padrão tecnológico, e aí a gente também confrontou com fatos e dados, ouvimos de forma bastante ativa eles, ouvimos a opinião do pessoal da manutenção dos operadores e do gerente de produção que tem uma larga experiência em confecção, então, toda essa vivencia a gente tem que respeitar, e utilizar do seu conhecimento, agora isso não quer dizer que você tem que abrir mão de ferramentas de análises, fatos e dados (Entrevistado D).

Subsequentemente ao exposto, ficou evidente que as decisões são tomadas em reuniões e de forma colegiada. Corroboram este olhar, por um lado, os estudos de Hart (1992) e Andersen (2004), os quais identificaram que a estratégia é estabelecida por distintos tipos ou modos, desde a tomada de decisão pela alta administração e, portanto, implementada no sentido de cima para baixo, indicando que as demais pessoas da organização devem agir somente pelo acatamento e pelo cumprimento das ordens, sem espaço para discussão do plano ou sugestões de melhoria. Assim como, modos mais participativos e que funcionam de forma mais integrativa e participativa, em que os diferentes praticantes tomam parte da decisão e das mudanças estratégicas.

Ainda nesse sentido, finalizando a análise dos praticantes, pode-se referir a Jarzabkowski, Balogun e Seidl (2007) os quais afirmam que as ações estratégicas, normalmente, são tomadas em um conjunto, mas também a formação da estratégia pode ultrapassar o interesse inerente à organização e passa a ser construída a partir dos interesses de cada tomador de decisão nas empresas.

Assim, considerando a perspectiva teórica e as evidências encontradas nos dados empíricos, em que se pode relacionar o processo e a estratégia como prática (BURGELMAN et al., 2018), pode-se voltar a aceitar a proposição elaborada inicialmente que: a tomada de decisão estratégica é definida a partir da análise do contexto organizacional (ambiente) e da ação dos praticantes (práticas estratégicas), no caso analisado. 
Diante disso, considerando a análise dos dados, evidenciou-se que todo o processo de tomada de decisão estratégica é realizado a partir de uma exaustiva análise do contexto organizacional, no qual é levado em consideração variáveis de mercado, política, recursos tecnológicos, entre outros, além da participação e das inferências dos praticantes que atuam no desenvolvimento e na implementação da estratégia; quando é necessária a tomada de uma decisão estratégica, os praticantes possuem forte influência nas escolhas, uma vez que eles, por meio da sua experiência e troca de conhecimento com os demais integrantes da empresa, realizam reuniões, pesquisa de mercado e análise do ambiente, definindo qual a melhor decisão estratégica a ser tomada. Ademais, já que as práticas são caracterizadas pelas rotinas, procedimentos e normas que surgem da estratégia acontecem de uma forma relacionada à cultura organizacional, ou seja, surgem da cultura já enraizada na organização (JARZABKOWSKI; BALOGUN; SEIDL, 2007).

\section{CONSIDERAÇÕES FINAIS}

O objetivo deste estudo foi compreender como ocorre o processo de tomada de decisão, a partir da análise das práticas estratégicas e da ação dos praticantes em uma indústria de confecção. Pode-se afirmar que esse objetivo foi alcançado, visto que foi possível identificar como a análise do contexto organizacional, somada à ação dos praticantes, teve influência nas tomadas de decisões dos gestores do caso em estudo.

As diferentes formas de análise do contexto organizacional que os gestores realizam têm gerado práticas interessantes à empresa, a qual, assim, consegue tomar suas decisões estratégicas de forma mais acertada.

As práticas estratégicas utilizadas pela organização, como reuniões, análise SWOT, planejamento estratégico definido, pesquisas de mercado e adoção de ferramentas de análise do ambiente externo vêm agregando valor para ela, visto que esta consegue ampliar seu mercado por meio de decisões mais precisas.
A partir da utilização em conjunto com pessoas de diferentes níveis hierárquicos da organização e das ferramentas citadas acima, evidenciou-se que a empresa consegue trabalhar na definição de estratégias importantes, as quais envolvem, principalmente, o lançamento de novas coleções e marketing.

Constatou-se ainda que as práticas estratégicas utilizadas pela empresa visam ao melhor aproveitamento dos recursos disponíveis, bem como levam em consideração a opinião das pessoas de diferentes níveis hierárquicos da empresa.

Isso proporciona à empresa uma vantagem competitiva, visto que todos os funcionários também se sentem parte importante na estratégia e, consequentemente, não medem esforços para que os objetivos sejam alcançados.

A contribuição teórica está centrada no avanço dos estudos acerca de como as práticas estratégicas e a ação dos praticantes contribuíram para a construção do marketing empresarial, aliando isso à análise do contexto organizacional e da participação colegiada de pessoas de diferentes níveis hierárquicos de uma organização. Essa contribuição corresponde ainda ao avanço de estudos de estratégia, como processo e prática apontado por Burgelman et al., (2018).

Como contribuição prática, gestores de empresas podem evidenciar e usar este caso, resguardando suas peculiaridades, como exemplo para a organização de sua empresa no que se refere a como as práticas estratégicas podem ser desenvolvidas por meio da ação dos praticantes. As pessoas que compõem o ambiente organizacional são peças-chave da empresa, são praticantes que podem trabalhar conjuntamente para construir estratégias mais acertivas.

As limitações desta pesquisa estão relacionadas às dificuldades de operacionalização do estudo, refletidas no reduzido número de entrevistas e documentos analisados, os quais estão vinculados à limitação do tempo de imersão no campo.

Como sugestões de futuras pesquisas, destaca-se, além de um tempo maior em campo para exploração em profundidade de entrevistas e análises de documentos, a necessidade de 
estudar, em uma realidade como esta, as ações individuais dos colaboradores, como as ações autônomas (ANDERSEN, 2000) e as táticas encobertas (covert tatics) (PRETORIUS, 2016) as quais contribuem para maior participação dos praticantes, correpondendo à abertura da estratégia (YAKIS et al., 2017).

A exploração deste tema é instigante e segue sendo de relevância para a academia e para as organizações, pois a evolução das teorias e das práticas, dos processos e das ações do dia a dia são elementos que contribuem para o crescimento e para o fortalecimento das organizações e das pessoas; servem de combustível para o avanço da ciência e das organizações.

\section{REFERÊNCIAS}

ABIT. Têxtil e confecção: Perfil do setor. 2016. Disponível em: http://www.abit.org.br/ cont/perfil-do-setor. Acesso em: 5 abr. 2017.

ANDERSEN, T. J. Strategic planning, autonomous actions and corporate performance. Long Range Planning, v. 33, n. 2, p. 184-200, 2000.

ANDERSEN, T. J. Integrating the strategy formation process: an international perspective. European Management Journal, v. 22, n. 3, p. 263-272, 2004.

BALOGUN, J.; HUFF, A. S.; JOHNSON, P. Tree Responses to the Methodological Challenges of Studying Strategizing. Journal of Management Studies, v. 40, n. 1, p. 1-28, 2003.

BULGACOV, S. et al. Administração estratégica: teoria e prática. São Paulo: Atlas, 2007. v. 10.

BURGELMAN, R. A. Complex strategic integration at nike: strategy process and strategy-as-practice combined. In: FLOYD, S. W.; WOOLDRIDGE, B. (ed.). The handbook of middle management strategy process research. Cheltenham, U.K.: Edward Elgar Publishing, 2017. p. 197-242.
BURGELMAN, R. et al. Strategy Processes and Practices: Dialogues and Intersections. Strategic Management Journal, v. 39, n. 3, p. 531-558, 2018.

CANHADA, D. I. D.; BULGACOV, S. Práticas sociais estratégicas e resultados acadêmicos: o doutorado em Administração na USP e UFRGS. RAP, v. 45, n. 1, p. 7-32, jan./fev. 2011.

CARDOSO, F. E.; LAVARDA, R. B. Perspectiva da estratégia-como-prática e o processo de formação da estratégia articulada pelo middle manager. REAd. Revista Eletrônica de Administração, Porto Alegre, v. 21, p. 719-749, 2015.

CHAKRAVARTHY, B. S.; DOZ, Y. Strategy process research: focusing on corporate self-renewal. Strategic Management Journal, v. 13, n. 1, p. 5-14, 1992.

CHIA, R.; MACKAY. B. Postprocessual challenges for the emerging strategy-as-practice perspective: Discovering strategy in the logic of practice. Human Relation, v. 60, n. 1, p. 217-242, 2007.

CZARNIAWSKA, B. On time, space, and action nets. Organization, v. 11, n. 6, p. 773-791, 2004.

CZARNIAWSKA, B. Organizing: how to study it and how to write about it. Qualitative Research in Organizations and Management: an international journal, v. 3, n. 1, p. 4-20, 2008.

CZARNIAWSKA, B. Organizations as obstacles to organizing. In: ROBICHAUD, D.; COOREN, F. (org.). Organization and organizing: materiality, agency and discourse.

New York: Routledge, 2013. p. 3-22.

D`AVILA, L. C. et al. A relação entre atores externos e estrategistas nas práticas estratégicas: um estudo exploratório em pequenas empresas. 
Revista Sinergia, v. 20, n. 2, p. 127-138, 2016. DIAS, A.T. B. B. B.; ROSSETTO, C. R.; MARINHO, S. V. Estratégia como Prática Social: um estudo de práticas discursivas no fazer estratégia. Revista administração contemporânea, Curitiba, v. 21, n. 3, p. 393-412, maio 2017.

EISENHARDT, K. M. Building theories from case study research. Academy of Management Review, Briarcliff Manor, v. 14, n. 4, p. 532-550, 1989.

EISENHARDT, K.; ZBARACKI, M. J. Strategic decision making. Strategic Management Journal, v. 13, p. 17-37, 1992.

ETZIONI, A. Organizações modernas. 8. ed. São Paulo: Pioneira, 1989.

FARACO, M. M.; LAVARDA, R. B.; GELB$C K E, F$. L. Tomada de decisão em hospitais de ensino: entre formalismo e síntese intuitiva. Revista de Administração Pública, v. 53, p. $1-13,2019$.

FELDMAN. M. S.; ORLIKOWSKI, W. J. Theorizing practice and practicing theory. Organization Science, v. 22, n. 5, p. 1240-1253, Sept./Oct. 2011.

GODOI, C. K.; BANDEIRA-DE-MELLO, R.; SILVA, A. B. da. Pesquisa qualitativa em estudos organizacionais: paradigmas, estratégias e métodos. São Paulo: Saraiva, 2006.

HAMBRICK, D. C. The top management team: key to strategic success. California Management Review, v. 30, n. 1, p. 88-108, 1987.

HART, S. L. An integrative framework for strategy-making processes. Academy of Management Review, v. 17, n. 2, p. 327-351, 1992.

IASBECH, P. A. B, LAVARDA, R. A. B. Strategy and practices: A qualitative study of a Brazilian public healthcare system of telemedicine.
International Journal of Public Sector

Management, v. 31, n. 3, p. 347-371, 2018.

JARZABKOWSKI, P. Strategic practices: an activity theory perspective on continuity and change. Journal of Management studies, v. 40, n. 1, p. 23-55, 2003.

JARZABKOWSKI, P. Strategy as practices: recursive, adaptive and practice-in-use. Organization studies, v. 25, n. 4, p. 489-520, 2004.

JARZABKOWSKI, P.; BALOGUN, J.; SEIDL, D. Strategizing: the challenges of a practice perspective. Human Relations, v. 60, n. 5 , p. 5-27, 2007.

JARZABKOWSKI, P. Activity theory approaches to studying strategy as practice: Cambridge handbook of strategy as practice. Cambridge: Cambridge University Press, 2010.

JARZABKOWSKI, P.; BURKE, G.; SPEE, P. Constructing spaces for strategic work: a multimodal perspective. British Journal of Management, v. 26, p. 26-47, 2015.

JARZABKOWSKI, P.; KAPLAN, S. Strategy tools-in-use: a framework for understanding 'technologies of rationality' in practice. Strategic Management Journal, v. 36, p. 537-558, 2015.

JARZABKOWSKI, P. et al. On the risk of studying practices in isolation: linking what, who and how in strategy research. Strategic Organization, v. 14, n. 3, p. 248-259, 2015.

JOHNSON, G.; MELIN, L.; WHITTINGTON, R. Micro Strategy and Strategizing: towards an Activity-Based View. Journal of Management Studies, v. 40, n. 1, p. 3-33, 2003.

KAPLAN, R. S.; NORTON, D. P. A estratégia em ação: balanced scorecard. 4. ed. Rio de Janeiro: Campus, 1997. 
KEENEY, R. L. Making Better Decision Makers. Decision Analysis, v. 1, n. 4, p. 193-204, 2004.

KRAKAUER. P. V. de C. A utilização das informações do ambiente no processo de decisão estratégica: estudo com empresários brasileiros e americanos de pequenas e médias empresas. 2011. Dissertação (Mestrado em Administração) - Universidade de São Paulo, São Paulo, 2011.

LAVARDA, R. B.; CANET- GINER, M. T.; PERIS-BONET, F. How middle managers contribute to strategy formation process: connection of strategy processes and strategy practices. Revista de Administração de Empresas, São Paulo, v. 50, n. 4, p. 358-70, 2010.

LAVARDA, R. B.; GINER, M. T. C.; BONET, F. J. P. Understanding how the strategy formation process interacts with the management of complex work. European Business Review, v. 23, p. 71-86, 2011.

LAWRENCE, Paul R.; LORSCH, Jay W. Organization and environment: managing differentiation and integration. Boston: Harvard University Press, 1967.

LIEBLICH, A.; TUVAL-MASHIACH, R.; ZILBER, T. Narrative research: reading, analysis, and interpretation. [S.l.]: Sage, 1998.

MINAYO, M. C. S.; ASSIS, S. G.; SOUZA, E. R. Avaliação por triangulação de métodos: abordagem de programas sociais. Rio de Janeiro: FIOCRUZ, 2005.

MIRABEAU, L.; MAGUIRE, S. From autonomous strategic behavior to emergent strategy. Strategic Management Journal, v. 35, n. 8, p. 1202-1229, 2014.

MIRABEAU, L., MAGUIRE, S.; HARDY, C. Bridging practice and process research to study transient manifestations of strategy. Strategic Ma- nagement Journal, v. 39, n. 3, p. 582-605, 2018. NICOLINI, D. Practice Theory, Work, e Organization. Oxford: [s.n.], 2012.

ORLIKOWSKI, W. J. Socialmaterial practices: exploring technology at work. Organization Studies, v. 28, n. 9, p. 1435-1448, 2007.

PRETORIUS, M. Crooked strategy implementation: covert tactics fill the gaps. Journal

of Business Strategy, v. 37, n. 4, p. 24-31, 2016.

RASCHE, A.; CHIA, R. Researching strategy practices: A genealogical social theory perspective. Organization Studies, v. 30, n. 7, p. 713734, 2009.

RECKWITZ, A. Toward a theory of social practices: a development in culturalist theorizing. European Journal of Social Theory, v. 5, n. 2, p. 243-263, 2002.

SCHATZKI, T. R. Introduction: practice theory. In: SCHATZKI, T. R.; CETINA, K. K.; SAVIGNY, E. The practice turn in contemporary. London: Routledge, 2001.

SCHATZKI, T. R. The sites of organizations. Organization Studies, v. 26, n. 3, p. 465-84, 2005.

SCHATZKI, T. R. On organizations as they happen. Organization Studies, v. 27, n. 12, p. 1863-73, 2006.

SILVA, A. B.; ROMAN NETO, J. Perspectiva multiparadigmática nos estudos organizacionais. In: GODOI, C. K.; BANDEIRA-DE-MELlO, R.; SILVA, A.B. (org.). Pesquisa qualitativa em estudos organizacionais: paradigmas, estratégias e métodos. São Paulo: Saraiva, 2006.

STAKE, R. E. Case studies. In: DENZIN, N.; LINCOLN, Y. Strategies of qualitative inquiry. Londres: Sage, 2003. p. 134-164. 
TEIXEIRA, M. G.; COSTA, M. C. De "fábrica Fundo de quintal" à empresa multinacional: o caso de uma aliança ítalo-brasileira sob o enfoque da abordagem estruturacionista da estratégia como prática. Revista Eletrônica de Administração, v. 18, n. 2, p. 521-551, 2012.

TROCHIM, W. M. K. Outcome pattern matching and program theory. Evaluation and Program Planning, v. 12, p. 355-366, 1989.

TURETA, C.; JÚLIO, A. C. Estratégia como prática na produção do desfile de uma escola de samba. In: ENCONTRO DE ESTUDOS EM ESTRATÉGIA, 7., 2015, Brasília. Anais [...]. Brasília: ANPAD, 2015.

VAN DE VEN, A. H.; JOHNSON, P. E. Knowledge for theory and practice. Academy of Management Review, Briarcliff Manor, v. 31, n. 4, p. 802-821, 2006.

WHITTINGTON, R. Strategy as practice. Long Range Planning, v. 29, n. 5, p. 731-735, 1996.

WHITTINGTON, R. Completing the practice turn in strategy research. Organization Studies, v. 27, n. 5, p. 613-634, 2006.

WHITTINGTON, R.; CAILLUET , L.; YAKIS-DOUGLAS, B. Opening strategy: evolution of a precarious profession. British Journal of Management, v. 22, n. 3, p. 531-544, 2011.

YAKIS, D. et al. Opening M\&A strategy to investors: predictors and outcomes of transparency during organisational transition. Long Range Planning, v. 50, n. 3, p.411-422, 2017. 